\title{
Autores ante críticos Bolaño/Belano ante Echevarría/Echevarne
}

\author{
Enrique RODRIGUES-MOURA \\ Institut für Romanistik \\ Universität Bamberg \\ enrique.rodrigues-moura@uni-bamberg.de
}

\begin{abstract}
RESUMEN
Este ensayo reflexiona sobre las muchas veces conflictivas relaciones entre autor y crítico en el marco del campo literario contemporáneo. Pone especial atención en el denominado "caso Echevarría" (2004), que enfrentó al crítico Ignacio Echevarría con el periódico El País (España) y que acabó provocando su dimisión por una colisión entre intereses culturales, empresariales e incluso ideológicos. Concluye con un análisis del proyecto literario de Roberto Bolaño y la necesidad poetológica de protegerlo de la crítica, hecho que se narra literariamente en la novela Detectives salvajes (1998) por medio de los personajes Arturo Belano (autor) e Iñaki Echevarne (crítico).
\end{abstract}

Palabras clave: Crítica literaria, campo literario, Roberto Bolaño, Ignacio Echevarría.

[Recibido, mayo 2014; aprobado, diciembre 2014]

Authors versus literary critics Bolaño/Belano versus Echevarría/Echevarne

\begin{abstract}
This essay ponders on the relationships between authors and literary critics in the contemporary literary field which is often in a state of conflict. It gives special consideration to the so-called "Echevarría case" (2004), in which the critic Ignacio Echevarría was confronted by the newspaper El País (Spain). This ultimately led to his resignation due to a clash of cultural, economical, as well as ideological interests. It closes with an analysis of Roberto Bolaños literary project and points out the poetological necessity of protecting it from literary criticism, especially considering that the novel Detectives salvajes (1998) is narrated through the characters Arturo Belano (author) and Iñaki Echevarne (literary critic).
\end{abstract}

Keywords: Literary criticism, literary field, Roberto Bolaño, Ignacio Echevarría. 
El primer interlocutor público y serio de un autor es el crítico literario. Previamente, es probable que algunos amigos del autor o algún lector de la editorial hayan tenido acceso al manuscrito y le hayan expresado su opinión, aconsejando o exigiendo modificaciones, esbozando, en suma, alguna eventual mejora concreta o una mayor reflexión de tal o cual aspecto. Todas estas sugerencias versan sobre una obra no terminada, por muy avanzado que se encuentre su estadio de redacción o incluso de corrección final. El autor suele acoger estos comentarios sobre su manuscrito, los comparta o no, con cierto interés y espíritu crítico. A fin de cuentas, ha sido él quien ha elegido a estos lectores de su libro en ciernes de conclusión. En el caso de sus lectores de confianza o amigos, no es menester glosar el motivo de su elección. En el caso del lector de la editorial, la capacidad de decisión del autor no es excesiva, pero en última instancia ha sido opción suya, o de su agente literario, dirigirse a esa editorial y no a otra. Es comprensible que las opiniones recibidas le inspiren algún desasosiego, pero por regla general las tendrá en cuenta. En el caso de sus lectores amigos, valorará las recomendaciones y, es de suponer, la empatía. En el caso del lector de la editorial, sabe de antemano que éste puede ser más duro en la formulación de su parecer, ya que no tiene por qué mantener una relación de confianza con él, pero este lector sólo realizará comentarios encaminados a mejorar el texto si ya existe, anterior en el tiempo, una decisión empresarial de publicar el libro. Sus comentarios tendrán, pues, un carácter profesional: consejos para que la calidad del libro sea mayor, según los criterios de la editorial, o para que se venda más, según los criterios del mercado. Ante todos estos consejos el autor puede reaccionar modificando o reafirmándose en sus opciones narrativas. Existe, pues, no sólo la posibilidad de un diálogo, por breve que éste sea, sino la posibilidad de que el autor modifique efectivamente algún pasaje de su libro. Por el contrario, una vez que el libro ya ha sido impreso, no hay posibilidad de que el autor vuelva a intervenir en su texto. Rara vez una editorial permite cambios significativos en una segunda edición.

El crítico literario, en consecuencia, puede que no sea el primer lector del libro, pero sí es el primero que hará pública sus opiniones, sus críticas. Y el autor ya no podrá tocar su texto. Le queda sólo el consuelo de, en algunos casos, rebatir también públicamente las críticas recibidas que considere injustas. Estos escritos de desagravio suelen provocar cierta vergüenza ajena en el lector imparcial, que sabe que lo mejor que un autor puede hacer, tras publicar su libro, es callarse, pues éste ya es un producto social, no más privado. Y este lector también sabe que, si la dura crítica proviniese de un medio de comunicación poco frecuentado, rara vez habría una reacción airada por parte del autor. Ahora bien, si el medio que ha publicado la feroz crítica a su libro posee cierto prestigio y lectores y, peor todavía para el autor, si a ello se une que esa voz proviene de un crítico que se ha labrado una cierta autoridad en el panorama literario, pocas opciones le quedan al autor para defenderse. El silencio es una de ellas. Otra consiste en embarcarse en un debate público de muy imprevisibles consecuencias, casi siempre muy esclarecedor para los no involucrados en la contienda. Una tercera opción suele tomarla la editorial, que puede movilizar, con la anuencia o no del autor, a críticos afines y medios de comunicación próximos para contrarrestar la voz crítica. Incluso banales pero poderosos medios publicitarios pueden entrar en liza, pues, como se sabe, a día de hoy la censura se ejerce de forma más elegante y mejor -sibilina, se podría añadir- hundiendo la noticia desagradable en un mar de otras nuevas, descaradamente elogiosas o simplemente neutrales. La abundancia de información es más efectiva que el recurso a la censura; en el hipotético caso de que se tenga poder para ejercerla. La vía judicial puede ser larga, costosa e imprevisible. 
A continuación, se presenta e interpreta un caso ya conocido -el denominado "caso Echevarría" (2004) - y se extraen algunas consecuencias sobre la siempre conflictiva relación entre autor y crítico literario. El "caso Echevarría" consistió en la demoledora crítica literaria que Ignacio Echevarría escribió en el diario El País sobre la novela El hijo del acordeonista, de Bernardo Atxaga (seudónimo de Joseba Irazu Garmienda), publicada por la editorial Alfaguara ${ }^{1}$. Hasta donde llegan mis informaciones, Bernardo Atxaga optó por un educado silencio público. El grupo empresarial español que editó su novela -dueño a la vez, entre otros medios, de El País y de la propia editorial Alfaguara-, por el contrario, adoptó una actitud beligerante, que acabó con la forzada dimisión de Echevarría de El País. El caso fue sonado y tuvo varias codas en las que llegaron a participar, directa o indirectamente, autores como Rafael Conte, Mario Vargas Llosa, Rafael Sánchez Ferlosio, Eduardo Mendoza, Javier Marías, Fernando Savater, etc., y también, de forma autónoma, Juan Goytisolo. Precisando, el "caso Echevarría" enfrenta, pues, más que a un crítico literario con un autor, a una empresa o conglomerado de empresas - grupo Prisa- con un crítico literario concreto Ignacio Echevarría-, al tiempo que pone sobre el tapete el poder que puede alcanzar un crítico literario que sepa negociar bien sus espacios de libertad crítica. El "caso Echevarría" muestra bien a las claras que la falta de un análisis apurado de estos espacios puede tener consecuencias devastadoras para el crítico, que acaba perdiendo su trabajo. A la vez, recuerda que un medio de comunicación que se precie de ser serio y destinado a lectores informados tiene que mantener y cultivar entre sus firmas la de algún crítico literario que se haya labrado una cierta autoridad e independencia en el panorama cultural. Es más, callar de forma inopinada la voz de un reputado crítico literario implica una merma significativa del respeto intelectual que se haya granjeado hasta entonces el respectivo medio de comunicación. Se agrieta el pacto de confianza que debiera existir entre un periódico y sus lectores. En ese sentido, la dimisión de Echevarría no fue en absoluto una buena noticia para El País.

Además, este citado "caso Echevarría" también recuerda, si bien de forma indirecta, que la voz del crítico puede llegar a ser temible para algunos escritores, especialmente para aquellos que vuelcan literariamente parte de su vida en sus textos -por muy retórica que pueda parecer, y es, la expresión-, para aquellos que intentan ir más allá de una fábula bien construida o alguna experimentación formal más o menos ingeniosa. En palabras del escritor Roberto Bolaño: “¿Entonces qué es una escritura de calidad? Pues lo que siempre ha sido: saber meter la cabeza en lo oscuro, saber saltar al vacío, saber que la literatura es un oficio peligroso" ("Discurso de Caracas" 36). En última instancia, las opiniones del crítico literario pueden ser dolorosas para aquellos escritores que buscan una cierta autenticidad en sus narraciones. En el marco de este razonamiento, concluiré este ensayo con una reflexión sobre el proyecto literario de Roberto Bolaño, deteniéndome de modo especial en dos personajes de la novela Detectives salvajes (1998): Arturo Belano, protagonista y escritor, e Iñaki Echavarne, crítico literario ${ }^{2}$.

\footnotetext{
${ }^{1}$ La novela había sido publicada el año anterior en vasco: Soinujolearen semea (editorial Pamiela).

2 Una primera versión de este ensayo fue publicada en alemán: Rodrigues-Moura, Enrique (2010): "Literaturkritiker und Schriftsteller im Duell. Ignacio Echevarría und Roberto Bolaño". Große Literaturkritiker. Sigurd Paul Scheichl (ed.). Innsbruck / Wien / Bozen: Studienverlag, 221-246.
} 
El crítico literario Ignacio Echevarría comenzó a trabajar de forma regular para el suplemento cultural Babelia, del periódico El País, en el año 1990. Entre esa fecha y el otoño de 2004, cuando abandonó definitivamente El País, publicó más de cuatrocientas reseñas críticas; sólo algunas de estas en otros medios, normalmente revistas españolas de literatura como Quimera, Revista de Libros, Lateral, etc. Únicamente una cuarta parte de estas reseñas versan sobre autores traducidos, a veces incluso ya clásicos, ya que desde su comienzo como crítico literario Echevarría mostró un claro interés por acompañar y discutir la literatura española contemporánea; ampliando su horizonte a la hispanoamericana a finales del siglo XX. Ya en 1996 Echevarría mostraba una clara conciencia de la función social del crítico literario, de su labor de orientador de lectores: "En un mundo confortablemente prejuzgado por las listas de ventas y los dictados de la academia, la crítica es aquel lugar donde todavía cabe una amenazante discrepancia." ("Glosas polacas" Trayecto 291). Y no sólo una voluntad de orientar a lectores más o menos bisoños, sino también a los propios autores más jóvenes: "Uno de los más útiles servicios que un crítico puede hacer al joven escritor consiste precisamente en señalar en su obra esos lugares comunes y esos manierismos de los que difícilmente se sustrae un libro primerizo." ("Los caníbales los prefieren jóvenes" Trayecto 294). Entre sus criterios literarios, Echevarría aboga por defender lo "nuevo" sin el elogio fácil a lo "último"; no reniega del texto literario con carácter político o social -comprometido, que se decía antes- y afirma de forma tajante que no todo vale. Es decir, no vale la pena perder el tiempo reseñando novelas que nacen con la vocación única de convertirse en un best seller. Sin atacar la legitimidad de un tipo de narrativa que únicamente busca el entretenimiento, Echevarría opta por unos "criterios de excelencia y de novedad literaria" ("Prólogo" Trayecto 27) que ha ido apuntando en sus reseñas, y por medio de contados artículos periodísticos, y que se podrían resumir en la renuncia a interpretar una novela según el baremo que aporta su éxito de ventas, entendido éste como criterio único y central de análisis. Además, en directa consonancia con su voluntad de intervención pública, orientadora de lectores e incluso autores, Echevarría ha sido siempre muy consciente de que sus críticas alcanzaban una importante repercusión no sólo por su más o menos meditado proyecto crítico, sino porque se publicaban regularmente en el suplemento cultural de El País. Sabía o intuía que unas bien labradas críticas pueden otorgar autoridad, pero la resonancia cultural sólo se logra si se escribe desde un medio de comunicación con gran difusión entre una importante masa de lectores formados y críticos. Y por último, sabía también Echevarría que para proteger su libertad crítica en esa ganada atalaya necesitaba amoldarse a algunas reglas no escritas, pero en absoluto desconocidas. Algunos autores próximos a la redacción de El País son intocables -el caso extremo sería el del exdirector y ocasional escritor Juan Luis Cebrián-, máxime cuando el grupo Prisa, empresa editora de El País, dirige los destinos de otros múltiples medios de comunicación -cadenas de radios, otros periódicos, cadenas de televisión- y la importante editorial Alfaguara. Algunos autores, pues, han estado siempre más o menos amparados de la crítica negativa en las páginas de El País. Cada medio de comunicación tiene sus autores intocables. Es así y es bueno saberlo de antemano.

El "caso Echevarría" comenzó el sábado cuatro de septiembre de 2004. Se trataba del primer sábado tras la vuelta de las vacaciones de agosto, la rentrée littéraire. El suplemento cultural de El País, Babelia, dedicó su portada a Bernardo Atxaga -fotografía a colores 
incluida-, así como las páginas dos y tres, en las que Javier Rodríguez Marcos publicaba una extensa entrevista con el autor. El suplemento Babelia presentaba la nueva novela de Atxaga, El hijo del acordeonista, publicada en vasco un año antes y por entonces recién traducida al castellano por la editorial Alfaguara ${ }^{3}$. La página cuatro se reservó por entero a la crítica literaria de la novela. Ignacio Echevarría firmaba dicha crítica, titulada "Una elegía pastoral", en la que se juzgaba con demoledora dureza la novela. El primer párrafo expresaba de forma elocuente la opinión de Echevarría:

Resulta difícil sobreponerse al estupor que suscita la lectura de esta novela. Cuesta creer que, a estas alturas, se pueda escribir así. Cuesta aceptar que, quien lo hace, pase por ser, para muchos, mascarón de proa de la literatura de toda una comunidad, la del País Vasco, cuya situación tan conflictiva reclama, por parte de quien se ocupa de ella, el máximo rigor y la mayor entereza. (4)

Pocas líneas más adelante, vuelve al ataque y resalta "el carácter tan tópico acusadoramente tópico, esta vez- de sus planteamientos narrativos, la enclenque consistencia de sus personajes, la poquedad de sus desarrollos." (4). Tras informar sobre la trayectoria del autor y sobre el enredo de la novela -datos básicos que todo crítico literario debe respetar-, Echevarría vuelve a expresar, negro sobre blanco, su opinión sobre la novela:

La beatitud y el maniqueísmo de sus planteamientos hace inservible El hijo del acordeonista como testimonio de la realidad vasca. A este respecto, la novela sólo vale como documento acrítico de la inopia y de la bobería - de la atrofia moral, en definitiva- que no han dejado de consentir y de amparar, hoy lo mismo que ayer, de forma más o menos melindrosa, el desarrollo del terrorismo vasco, reducido aquí a un conflicto de lobos y pastores, un problema de ecología lingüística y sentimental, al margen de toda consideración ideológica. (4)

Antes de su publicación, la crítica fue leída, se supone, por la entonces directora del suplemento cultural Babelia, María Luisa Blanco, que no puso ningún reparo significativo. El director adjunto de El País, responsable de Opinión y del suplemento Babelia, Lluís Bassets, posiblemente no llegó a leer la crítica, o por lo menos no con la debida atención, pues luego, una vez ya publicada, se erigió en severo censor de la opinión de Echevarría. Como se llegó a saber algunos meses después, la Redacción de Babelia sólo censuró una frase. Dicha frase, que seguía al párrafo inicial y que, a su vez, constituía un párrafo autónomo, lo que resaltaba aún más su importancia, rayaba el ataque personal. La frase se puede leer en la recopilación que el propio Echevarría ha hecho de una parte importante de sus reseñas: "Ocasiones hay en que la indigencia narrativa admite ser tomada por indicio de incompetencia moral. Ésta parece ser una de ellas." (Trayecto 283).

El posible efecto negativo que la crítica de Echevarría haya podido ejercer en las ventas de la novela de Atxaga fue ciertamente escaso. Aparte de que hubo otras críticas elogiosas en otros periódicos o revistas, cualquier lector, oyente o espectador atento de alguno de los medios de comunicación englobados en el grupo Prisa pudo percibir que en las semanas siguientes a su publicación se sucedieron incontables reclamos publicitarios de la más variada índole que, se podría interpretar, buscaban contrarrestar ese efecto negativo que podría conllevar la crítica de Echevarría. Algunos medios de comunicación rivales percibieron e informaron sobre esa constante presencia de la novela de Atxaga en los medios del

\footnotetext{
${ }^{3}$ En concreto, la traducción se debe al propio autor y a su esposa, Asun Garikano.
} 
grupo Prisa. Más llamativo fue, si cabe, una ausencia, especialmente por no mediar ninguna justificación por parte de la redacción de El País: desde ese aciago sábado cuatro de septiembre de 2004 la firma de Echevarría desapareció del suplemento cultural Babelia.

El caso podría haberse cerrado de esa forma para el gran público, por lo menos para los lectores de El País, pero no fue así. Alrededor del 9 de diciembre de ese mismo año, luego transcurridos más de dos meses desde las feroces letras contra la novela de Bernardo Atxaga, comenzó a circular en internet una carta abierta de Ignacio Echevarría dirigida a Lluís Bassets, en su función de director adjunto de El País. En la parte inicial de dicha carta Echevarría repasaba los hechos conocidos: la publicación de su demoledora crítica y la posterior andanada de "artículos, entrevistas y crónicas" ("Carta abierta a Lluís Basset", en línea) con la finalidad de neutralizar dicha crítica. A continuación, aportaba algunas reflexiones personales sobre su papel de crítico literario en El País: “¿Tiene sentido tratar de hacer una crítica más o menos exigente e independiente en un medio que parece privilegiar y defender a ultranza, sin el mínimo decoro, los intereses de una editorial que pertenece a su mismo grupo empresarial?" Más adelante, informaba de hechos desconocidos para el lector: su siguiente crítica literaria, que versaba sobre la traducción al castellano del ya clásico libro El bosque sagrado, de T. S. Eliot, seguía sin publicarse desde el 13 de octubre y, más grave, no había recibido ninguna explicación por parte de los responsables del periódico $\mathrm{y}$, en concreto, del destinatario principal de esa carta abierta, Lluís Bassets. Según Echevarría, el 28 de octubre habría preguntado por escrito el motivo de la tardanza a la hora de publicar esa nueva reseña. En esa misma misiva también habría recordado los catorce años que llevaba colaborando con el periódico El País. El 29 de octubre, escribe Echevarría, recibió una respuesta de Bassets, en la que se le comunicaba que él personalmente había retenido esa reseña crítica y añadía, siempre según la carta abierta de Echevarría: "Se ha dicho [...] y supongo que te habrá llegado, que tu crítica era como un arma de destrucción masiva y que el periódico hace mucho tiempo que ha renunciado a utilizar este tipo de armas contra nadie." Por lo visto, según Echevarría, fue el director de El País, a la sazón Ignacio Ceberio, quien habría utilizado la bélica expresión, a voz en grito y ante testigos. Ironizaba en su carta abierta Echevarría sobre el tono "halagador" de la frase, para él y para la profesión, pues implicaba que una crítica literaria podía alcanzar, metafóricamente, una fuerza militar incontrolable. Concluía Echevarría su carta recordando que no era la primera vez que había utilizado un tono "demasiado tajante y descalificatorio". Enumeraba, en concreto, cuatro ejemplos, las recientes críticas que había escrito sobre sendas novelas de Jorge Volpi, Antonio Skármeta, Jaime Bayly y Lorenzo Silva; ninguna de ellas publicada por la editorial Alfaguara. Una sencilla búsqueda en la hemeroteca localiza sin mayores problemas las críticas citadas y una rápida lectura de éstas arroja las siguientes frases, que corroboran la afirmación de Echevarría. El lector puede juzgar por sí mismo:

\footnotetext{
[Jorge Volpi. El fin de la locura. Barcelona: Seix Barral, 2003]

En la ardua travesía de esta novela, colabora decisivamente la incredulidad que no para de suscitar. De página a página, el lector va diciéndose que no es posible, que sin duda hay algo que se le escapa: registros paródicos, claves ocultas que se revelarán de pronto cuando se tensen los hilos de la delirante trama. A medio camino, abandonada ya cualquier esperanza de arreglo, lo que aún sostiene la lectura es una curiosidad casi morbosa: ¿hasta dónde será capaz de llegar la novela en su creciente disparate? [...] Volpi sucumbe a todos los riesgos a los que imprudentemente se expone, demasiado confiado en su talento. El resultado es una novela que, aunque llena de intenciones críticas y humorísticas, no arranca una sola risa, y que lejos de mover a la reflexión, o a la polémica, o a la indignación, sólo produce pasmo y bostezo. (Echevarría Desvíos 160-162)
} 


\begin{abstract}
[Antonio Skármeta. El baile de la Victoria. Barcelona: Planeta, 2003]
Decía André Gide, o venía a decir, que con buenos sentimientos no se hace buena literatura. Un prejuicio más que discutible que se confirma sin embargo irrefutablemente cuando esos buenos sentimientos son empleados con intención aduladora por un escritor dispuesto a ganarse a cualquier precio el ánimo de sus lectores, a quienes trata como niños bobos frente a los que él mismo ejercita toda suerte de zalamerías. [...] Y es que no se trata sólo de un argumento escuálido y mil veces repetido. No se trata sólo de personajes estereotipados y de situaciones preconcebidas. Se trata además de los trazos increíblemente burdos con que se dibuja la más burda de las novelas, artificiosamente inflada -para más inri- con los expedientes más peregrinos: aquí una postalita turística, allí una viñeta costumbrista o una pintoresca estampa de hamponería; más acá un "colorido" diálogo en chileno castizo, más allá unas gotitas de crítica social, o una lección filosofal, o una proclama ecológica, o un ripio ecuménico, o - para que nada falte- una sonrojante escena de sexo diluida en el más rijoso lirismo, todo en forma de aplicados ejercicios de taller literario. (Echevaría "El escritor imaginado" 10)
\end{abstract}

[Jaime Bayly. El huracán lleva tu nombre. Barcelona: Planeta, 2004]

[...] [S]u instinto de narrador ha quedado al parecer definitivamente atrofiado. [...] Por otra parte, hace ya mucho tiempo que Bayly, glamoroso y mediático, encarna como nadie un modelo de estatus gay convenientemente pasteurizado, liofilizado y homogeneizado. Con aburrimiento y cinismo crecientes, sus novelas tienden a ilustrar, antes que a explorar, una pose y una sentimentalidad abiertamente kitsch, que en sus momentos más atrevidos confunde exhibicionismo con transgresión. (Echevarría Desvíos 75-77)

[Lorenzo Silva. Carta blanca. Madrid: Espasa, 2004]

En el panorama de la actual narrativa española, Lorenzo Silva es uno de los mejores exponentes de lo que, sin reticencias de ningún tipo, cabe entender por escritor profesional. Es ésta una especie particular de escritor sin demasiadas ínfulas intelectuales ni artísticas, solvente, concienzudo a su manera, técnicamente bien pertrechado, y muy sensible a los gustos y a las demandas del gran público. Sin preocuparse mucho por su propio carisma, y sin andarse en general con manías, el escritor profesional se entiende bien con una industria editorial a la que sirve eficazmente y que le sirve a él para labrarse una próspera carrera [...]. (Echevarría Trayecto 276)

Los ejemplos son elocuentes: "incredulidad", "creciente disparate", "pasmo y bostezo", "intención aduladora", "zalamerías", "personajes estereotipados", "artificiosamente inflada", "rijoso lirismo", "aburrimiento y cinismo", "sin demasiadas ínfulas intelectuales ni artísticas", etc. No sólo muestran el poco aprecio que Echevarría sintió por estas novelas, sino también sobre su particular concepción de la literatura. El lector puede constatar que el tono de estas críticas no divergía del tono empleado en su reseña de la novela El hijo del acordeonista de Bernardo Atxaga.

Visto que entre el 29 de octubre y el 9 de diciembre Bassets no se había puesto en contacto con Echevarría, la carta abierta no podía concluir de otra manera: Echevarría dimitía de su función de crítico literario del suplemento Babelia. En el penúltimo párrafo de su carta abierta expresaba con claridad, desde su punto de vista, el meollo intelectual e incluso político de su repentina ausencia de las páginas de El País:

Pero lo que me preocupa de verdad es que El País, del que vengo siendo lector desde hace más de veinte años, y donde vengo escribiendo desde hace catorce, pueda ejercer de un modo abierto la censura y vulnerar interesadamente el derecho a la libertad de expresión, del que tan a gala tiene ser defensor y valedor. Eso, y no otra cosa, es lo que se desprende de la resolución de vetar a un antiguo colaborador por el solo motivo de haber manifestado contundentemente, sí, pero también argumentadamente, su juicio negativo acerca de una novela. (Echevarría "Carta abierta a Lluís Basset”, en línea) 
La carta abierta de Echevarría a Bassets circuló generosamente por internet. Aproximadamente diez días después, el 18 de diciembre, nada menos que 74 "críticos, redactores, escritores, lectores y colaboradores de EL PAÍS", encabezados por Rafael Conte, Mario Vargas Llosa, Rafael Sánchez Ferlosio, Juan Marsé, Eduardo Mendoza y Félix de Azúa, entre otros, firmaban una carta al director en la que expresaban su "preocupación por el daño que ha sufrido el crédito del periódico a raíz de la carta abierta" que Echevarría había enviado a Bassets ("Preocupación" 15) ${ }^{4}$. La lista de firmantes era ciertamente muy variopinta. Interpretar el real grado de preocupación de cada uno de ellos es tarea imposible, pero el lector puede suponer, quizás equivocadamente, quizás acertadamente, que Ignacio Echevarría habría rechazado de forma categórica el apoyo de alguno de ellos. Barajo para esta afirmación tanto motivos poetológicos como ideológicos. A título de ejemplo clarificador, entre los firmantes se encuentra Juan Manuel de Prada, escritor a quien Echevarría disfrazó de centurión romano en una crónica de las Navidades de 2009 ("Cuento de Navidad", en línea).

Interpretaciones aparte, un periódico que se precie de serio no puede ignorar una carta al director de tal calibre crítico y menos si viene avalada por firmas de peso en el espacio cultural de la lengua española. Así, a toda prisa, al mismísimo día siguiente, el 19 de diciembre, tuvo que intervenir la periodista Malén Aznárez, por entonces Defensora del Lector de El País, publicando un artículo encabezado por el elocuente título de "El "caso Echevarría"”. Comienza Aznárez su artículo señalando que "casi una veintena" ("El "caso Echevarría" 16) de lectores le ha enviado quejas sobre la falta de explicaciones respecto a la prolongada ausencia de la pluma de Ignacio Echevarría del suplemento cultural Babelia. Cumplidora y eficiente, Aznárez preguntó a María Luisa Blanco, redactora jefa de Babelia, sobre el ya largo eclipse de Echevarría. Sus respuestas, transcritas por Aznárez, fueron muy informativas: "Después de la publicación de la crítica de Atxaga, el director, Jesús Ceberio, me pidió públicamente que comunicara al crítico que este periódico no utiliza 'bombas atómicas' contra nadie" (16). La semántica bélica aplicada a la crítica literaria de Echevarría seguía aportando matices. Subiendo en la escala jerárquica, Aznárez se dirigió a Lluís Bassets, responsable, en última instancia, del suplemento Babelia. Bassets niega tajantemente que haya habido censura, pues a fin de cuentas la crítica se publicó, y también refuta la acusación de que haya habido una "limitación al derecho a la información y a la libertad de expresión" (16). Argumenta que los lectores son libres de "elegir el diario que quieren leer", así como las "empresas periodísticas" de elegir los artículos que desean publicar (16). No es necesario ser un gran conocedor del panorama periodístico español para percibir cierto oportunismo en el trasfondo de ambas afirmaciones: libertad de elección de los lectores y libertad de elección de las empresas periodísticas. A finales del año 2004 no existía en España más que un diario de información general solvente que se situase en el centroizquierda del espectro político. Ese diario era El País. Con su afirmación, muy legítima, Bassets sabía que algunos lectores se podrían soliviantar, y con razón, pero la alternativa era prácticamente nula. El País no tenía competencia: los demás periódicos o no eran de información general, o se circunscribían a su comunidad autónoma, o eran marcadamente con-

\footnotetext{
${ }^{4}$ La lista completa incluye, entre otros, a Fernando Savater, Javier Marías, Ray Loriga, Juan Manuel de Prada, etc. El lector curioso la encuentra fácilmente en internet; por ejemplo, en escolar.net.
} 
servadores, o eran acentuadamente sensacionalistas ${ }^{5}$. Continuaba Aznárez en su texto glosando o citando las respuestas de Bassets. La carta abierta de Echevarría había sentado muy mal: el asunto se había hecho público y las críticas habían llovido. No habían gustado a Bassets las formas de Echevarría.

En su indagación por la redacción de El País, Aznárez llegó al director, Jesús Ceberio, que no tuvo empacho en afirmar, de forma rotunda, siempre según Aznárez, que el "conflicto" se había gestionado "muy mal", pero niega la mayor cuando se menciona la posibilidad de que se haya cercenado la libertad de expresión y de crítica ("El "caso Echevarría"” 16). En sus conclusiones, Aznárez considera que "el desarrollo" del conflicto había sido "un auténtico disparate" (16). Y avanza más.

No sólo debían haberse extremado todo tipo de precauciones para evitar el conflicto y las sospechas, sino que antes que nada debió de hablarse con Echevarría en vez de mantener silencio durante tres meses. Si, como ha asegurado Jesús Ceberio, la decisión no fue prescindir del mismo, "sino congelar la relación durante un tiempo", parece de locos haber llegado a una situación que ha desembocado en la pérdida de un crítico de prestigio, y dado pie a graves repercusiones para la credibilidad del periódico $(16)^{6}$.

Aznárez cierra su artículo dando a entender que en casos como éste es donde una bien labrada credibilidad se puede perder fácilmente. Lamentablemente, en su puntilloso recorrido por la redacción de El País, de María Luisa Blanco a Lluís Bassets hasta llegar a Jesús Ceberio, Aznárez olvidó pedir la opinión de la otra parte, de quien ya se había autoexcluido de la redacción, de Ignacio Echevarría. Tremendo lapsus que le echa en cara el propio Echevarría en una Carta al Director aparecida al día siguiente, el 20 de diciembre: "Quiero expresar, en primer lugar, mi sorpresa por el hecho de que se pueda tratar por extenso el caso Echevarría, como lo llama la Defensora del Lector, sin darme voz alguna" "“Caso Echevarría"” 15). Entrando en materia, toca Echevarría un punto crucial, el económico. A la

\footnotetext{
${ }^{5}$ Resulta pertinente citar dos hechos periodísticos ocurridos desde entonces. El primero se materializó el domingo 21 de octubre de 2007, cuando El País cambió su histórica cabecera: de "Diario independiente de la mañana" se pasó a leer "El Periódico global en español". El cambio perseguía afianzar la fuerte expansión internacional del diario. Ese 21 de octubre de 2007, no obstante, se podía leer en su portada: "El líder de la prensa en español potencia sus contenidos y renueva su diseño con el reto de reforzar su compromiso con la independencia, la calidad y la credibilidad." No pocos lectores lamentaron que precisamente por un "compromiso con la independencia" se eliminase el adjetivo "independiente" de la cabecera del diario. El segundo hecho periodístico relevante tuvo lugar un mes antes de ese cambio de cabecera, concretamente el 26 de septiembre de 2007, día en que salió al mercado español el periódico de información general denominado Público. Este nuevo medio nació con la vocación de captar sobre todo a los lectores escorados más hacia la izquierda, y marcadamente más jóvenes que los lectores habituales de El País. La guerra periodística y empresarial entre ambos medios fue, desde entonces, muy enconada, y las malas artes estuvieron reiteradamente presentes. Con el cierre de la versión en papel de Público, en febrero de 2012, El País ha consolidado su hegemonía no sólo como medio de comunicación de masas más leído de España, sino, sobre todo, con mayor penetración entre los lectores identificados ideológicamente con el centro y en el centro-izquierda político. Es obvio que los medios conservadores o muy conservadores han aprovechado el "caso Echevarría" para atacar sin piedad lo que consideran una falta de libertad en el periódico líder del mercado español. No es objeto de este ensayo discutir esas acusaciones ni su marcado tono oportunista, ahí sí acentuadamente oportunista.

${ }^{6}$ Resulta interesante notar que Malén Aznárez opta en su texto por la construcción "deber de + infinitivo" ("debió de hablarse"), que, como se sabe, denota probabilidad o suposición, habiendo tenido a mano la posibilidad de elegir la construcción "deber + infinitivo", que hubiese implicado un sentido de obligación.
} 
espera de una prometida respuesta de Lluís Bassets, optó, cuando sintió que ya no la recibiría, por un gesto que eliminaba de raíz cualquier compromiso entre las partes: dimitir por medio de una carta abierta en internet. Se trataba de un gesto sin vuelta atrás e implicaba renunciar a "un medio de sustento" que, por poco que pudiese significar, nunca se debería menospreciar (15).

Un crítico literario no es más que un asalariado de un periódico, a veces en nómina, a veces como simple colaborador. Quizás fue ahí donde no midió bien Echevarría el poder que le otorgaba su trabajada autoridad como crítico, folio a folio durante catorce años. Otra Carta al Director de ese mismo día 20 de diciembre muestra bien a las claras que Echevarría se había hecho muchos enemigos, algunos irreconciliables. La firma Justo Serna, profesor de Historia en la Universidad de Valencia, frecuente colaborador de El País y autor, entre otros libros, de un título sobre el escritor Antonio Muñoz Molina: Pasados ejemplares. Historia y narración en Antonio Muñoz Molina (2004). Considera Serna que la misiva de los intelectuales preocupados por la posible censura de la libertad de expresión en El País es "pertinente", pero al mismo tiempo lamenta no haber visto "el más mínimo reproche a Echevarría, un crítico atrabiliario que ha juzgado, condenado, vilipendiado o ensalzado libros más allá de sus virtudes" ("Caso Echevarría"” 15). Serna no pertenece ideológicamente al ámbito conservador, que por esos días tanto disfrutaba con el "caso Echevarría", como deja claro en su carta, pero siempre consideró a Echevarría un crítico injusto, luego no llega a comprender tales dosis de solidaridad ${ }^{7}$. Considera, además, que el único que en su momento ya se había enfrentado a Echevarría fue el escritor Muñoz Molina, con un texto titulado "En folio y medio", que se publicó en El País el 9 de octubre de 1996. En este sentido, interesa observar que precisamente el nombre de Muñoz Molina no constaba en la lista de esos 74 intelectuales que, aludiendo al posteriormente denominado "caso Echevarría", habían mostrado su preocupación por la posible falta de libertad de crítica en el diario El País. Indudablemente, Ignacio Echevarría se había forjado enemigos a lo largo de sus catorce años en la atalaya de Babelia y no calibró bien sus fuerzas, sus espacios de libertad en una empresa periodística con tantas ramificaciones en la industria de los medios de comunicación y de la cultura.

Y no sólo en el ámbito de la cultura. La novela de Atxaga versaba, por lo menos en parte, sobre los orígenes del nacionalismo vasco, sobre la supuesta lucha fratricida de un pueblo, luego la política era un sustrato básico de su libro. Echevarría divergía de los planteamientos políticos plasmados por Atxaga en su novela, de su interpretación de los más de cuarenta años de violencia y terrorismo en el País Vasco. Además, el lector atento recordará que por esas fechas el consenso antiterrorista entre las fuerzas del arco parlamentario español comenzaba a deteriorarse a ojos vista. Un editorial de El País del cinco de septiembre de 2004 acusaba a José María Aznar de deber una explicación pública por no haber convocado el Pacto Antiterrorista horas después del atentado del 11 de marzo de ese año, y meses más

\footnotetext{
${ }^{7}$ El periodista Víctor de la Serna, en las páginas de El Mundo, cabecera rival de El País, atacó con infeliz ironía a Justo Serna, acusándolo de haber salido en apresurada defensa del grupo Prisa, hecho que Serna desmintió a la primera ocasión. Como se ha comentado en una nota anterior, se ignoran en este artículo las oportunistas intervenciones publicadas en otros medios que, en defensa de la libertad de expresión, en realidad sólo respondían a una rivalidad empresarial. También en las páginas de El Mundo, la escritora Lucía Etxebarría despotricó contra Ignacio Echevarría y contra todos los críticos orgullosos y ambiciosos.
} 
tarde, otro editorial, esta vez del 13 de mayo de 2005, afirmaba sin ambages que Mariano Rajoy había quebrado el consenso antiterrorista. Ese mismo lector atento podría interpretar una anuencia e incluso apoyo, por esos meses, de la línea editorial de El País a la política antiterrorista desplegada por el gobierno de José Luis Rodríguez Zapatero y podría sentir o intuir que la reseña crítica de Ignacio Echevarría no fuese, por ello, muy oportuna.

Como el propio Echevarría ha contado, sus inicios como crítico literario en El País tuvieron que conseguir la "luz verde" de Joaquín Estefanía, por entonces director del periódico, ya que sus críticas concretas sobre El manuscrito carmesí (1990), de Antonio Gala, autor que por entonces publicaba regularmente en El País, y El camino del corazón (1990), de Fernando Sánchez Dragó, eran ciertamente demoledoras (Trayecto 43). Catorce años y muchas reseñas después las tornas habían cambiado y Jesús Ceberio sólo pudo lamentar que el "caso Echevarría" hubiese sido tan mal llevado.

El "caso Echevarría" aún tuvo un coletazo algunas semanas después, concretamente el 28 de enero de 2005, cuando el escritor Juan Goytisolo publicó en El País un artículo en el que consideraba que la carta abierta de Echevarría exigía una "reflexión y la apertura de un debate en torno a la difícil independencia del crítico respecto a los intereses empresariales y, añadiría yo, a las consideraciones de corrección política que a menudo la traban" ("Cuatro años después" 16). Consideraba Goytisolo, a modo de continuación catastrofista de otro artículo suyo, "Vamos a menos", publicado cuatro años antes también en El País, que la situación cultural de España no tenía visos de mejorar, ya que los intereses empresariales son demasiado poderosos y se inmiscuyen inmisericordemente en los espacios reservados al espíritu crítico. Respecto al caso en cuestión, Goytisolo incluso afirmaba que "lo que asombra e inquieta a muchos lectores es que Ignacio Echevarría haya tardado catorce años en advertir dicha situación" (16). La respuesta del aludido llegó al día siguiente y en el mismo medio. Lamenta Echevarría las "jeremiadas imprecisas" de Goytisolo, pues sólo "la concreta denuncia de una situación determinada contribuye a un debate real del estado de las cosas" ("Respuesta a Goytisolo" 14). En este sentido, algunos años antes, en abril de 1998, Echevarría ya había criticado con crudeza "los peculiares derroteros seguidos" ("Un círculo vicioso" 41) por la obra de Goytisolo. En esa ocasión le había criticado tanto su insistencia literaria en un "cliché de un país y de una cultura" como el "solapamiento de su proyecto literario con su proyecto personal", llegando a calificar su "mitomaníaca infautación" de, curiosamente, "caso Goytisolo" (41). De todas formas, enfrentado a las palabras de Goytisolo de enero de 2005, Echevarría parece aceptar, no obstante, de forma algo indirecta, que no es imposible que en los últimos tiempos los límites en los que se puede mover la libertad de la crítica literaria "se hayan entretanto estrechado" ("Respuesta a Goytisolo" 14). Busca, de todas formas, distanciarse del envenenado apoyo prestado por Goytisolo, consciente, quizás, de que, perdido su espacio de libertad crítica en El País, no valía la pena enzarzarse en batallas reivindicativas harto inciertas. No era cuestión de seguir ampliando los capítulos del "caso Echevarría". 
El proyecto literario de Roberto Bolaño (1953-2003), como el de la mayoría de los escritores, fue conformándose según se iban publicando sus poemas y libros. Tanto en los textos de ficción como en los de no ficción, Bolaño fue pergeñando con mayor o menor claridad ese proyecto literario, siempre en constante evolución, pero con un par de ideas permanentes. Por un lado, la consideración de que la literatura es algo más que un juego o, dicho con otras palabras, que la literatura es un juego que hay que tomarse muy en serio, pues es la vida de uno mismo la que entra en liza. Para no entrar aquí en disquisiciones sobre las relaciones establecidas entre literatura y vida, binomio de larga tradición en la historia de la literatura occidental, lo mejor es volver a citar sus propias palabras: “¿Entonces qué es una escritura de calidad? Pues lo que siempre ha sido: saber meter la cabeza en lo oscuro, saber saltar al vacío, saber que la literatura es un oficio peligroso" ("Discurso de Caracas" 36). Por otro lado, Bolaño ha mostrado siempre una vocación de recordar literariamente a una generación de latinoamericanos - más concretamente, un grupo importante de miembros de una generación cronológica, que es la suya- que creyeron en el sueño de la revolución. Una generación que luchó por un ideal político, no pocas veces con el recurso de las armas, y que fracasó en el intento. Una generación que despertó con la Revolución Cubana de 1959, generadora de un sueño continental latinoamericano de izquierdas, que vivió una trágica derrota en la matanza de Tlatelolco, en octubre de 1968, y que confirmó su fenecimiento el 11 de septiembre de 1973, con el golpe de Estado que derrocó al presidente chileno Salvador Allende. En versos de Bolaño:

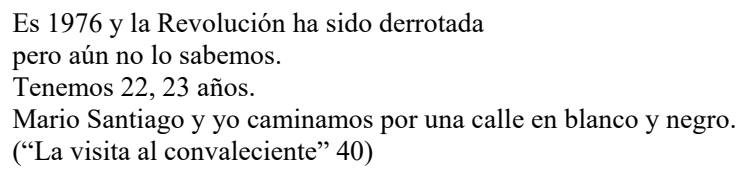

Esta voluntad de recordar a su generación y los sueños utópicos de ésta adopta un carácter de construcción de una memoria colectiva, en el sentido de Halbwachs, o, más específicamente, de una memoria comunicativa, tal y como la define Assmann: aquella memoria que se transmite de generación a generación: abuelos, padres e hijos. La memoria comunicativa de los portadores de este sueño utópico fracasado no ha pasado a formar parte de los discursos nacionales y hegemónicos latinoamericanos precisamente por su derrota, por lo que rescatarla implica un compromiso ético necesario.

Con motivo de la concesión del Premio Rómulo Gallegos a su novela Los detectives salvajes (1998), Bolaño pronunció en Caracas el dos de agosto de 1999 una conferencia de agradecimiento. En ella esboza sucintamente lo que él considera el objetivo de su literatura:

[...] [E]n gran medida todo lo que he escrito es una carta de amor o de despedida a mi propia generación, los que nacimos en la década del cincuenta y los que escogimos en un momento dado el ejercicio de la milicia, en este caso sería más correcto decir la militancia, y entregamos lo poco que teníamos, lo mucho que teníamos, que era nuestra juventud, a una causa que creímos la más generosa de las causas del mundo y que en cierta forma lo era, pero que en la realidad no lo era. (Bolaño "Discurso de Caracas" 37)

Este pasaje citado muestra el sueño utópico de su juventud, su lado idealista, y la interpretación de éste años después, tras su fracaso. Inmediatamente antes de esas palabras, Roberto Bolaño citaba y comentaba el famoso discurso de don Quijote sobre las armas y las 
letras (Quijote, I, capítulos 37 y 38) y mostraba una evidente comprensión por la opción quijotesca de las armas, el "fantasma de su juventud perdida" ("Discurso de Caracas" 37).

Para no basar esta interpretación aquí propuesta únicamente en los textos no ficcionales de Bolaño, luego en su propia estilización literaria, es pertinente observar un par de pasajes de una novela de ese mismo año de 1999, Amuleto. La protagonista y narradora, Auxilio Lacouture, personaje que también aparece en Los detectives salvajes, da principio a su narración especificando su género literario: "Ésta será una historia de terror. [...] Pero no lo parecerá. [...] Pero en el fondo es la historia de un crimen atroz" (Bolaño Amuleto 11). Y el crimen será explicado en las últimas páginas, cuando la protagonista vea y quizás comprenda:

\footnotetext{
Y supe que la sombra que se deslizaba por el gran prado era una multitud de jóvenes, una inacabable legión de jóvenes que se dirigía a alguna parte. [...]

Supe también que pese a caminar juntos no constituían lo que comúnmente se llama una masa: sus destinos no estaban imbricados en una idea común. Los unía sólo su generosidad y su valentía. [...] Los niños, los jóvenes, cantaban y se dirigían al abismo. [...]

Y los oí cantar, los oigo cantar todavía, ahora que ya no estoy en el valle, muy bajito, apenas un murmullo casi inaudible, a los niños más lindos de Latinoamérica, a los niños mal alimentados y a los bien alimentados, a los que lo tuvieron todo y a los que no tuvieron nada, [...] marchaban hacia una muerte cierta. [...]

Y aunque el canto que escuché hablaba de la guerra, de las hazañas heroicas de una generación entera de jóvenes latinoamericanos sacrificados, yo supe que por encima de todo hablaba del valor y de los espejos, del deseo y del placer.

$\mathrm{Y}$ ese canto es nuestro amuleto. (Amuleto 151-154)
}

Recordar ese sacrificio -el sueño de esa generación- viene a ser como poseer el objeto mágico que tiene la virtud de alejar el mal o propiciar el bien: el amuleto. Las páginas de la novela, en cuanto que recuerdan, se convierten en el amuleto deseado y en consecuencia escribir pasa a ser una forma de recordar: un amuleto. Toda vez que Bolaño forma parte de esa generación, escribir es recordarse a sí mismo, luego la escritura y la vida van a la par.

En varias novelas de Bolaño se puede leer que un personaje posee un aura especial tras haber experimentado en sus carnes la existencia del mal, tras haber entablado relaciones con el diablo o haber estado a las puertas del abismo. El propio alter ego de Roberto Bolaño, el personaje Arturo Belano, sería un ejemplo. En la citada novela Amuleto, Belano abandona México en 1973, poco antes del golpe, para "volver a su patria a hacer la revolución" (63), y así cumple un itinerario parecido al que Roberto Bolaño también hizo y que forma parte de su biografía de autor. Las vivencias durante el golpe de Estado no se especifican en la novela, pero la protagonista y narradora informa al lector de su significado: "Cuando Arturo regresó a México, en enero de 1974, ya era otro. [...] [A] hora estaba instalado en la categoría de aquellos que han visto a la muerte de cerca, [...]. [C]omo si él fuera el Dante y acabara de volver del Infierno, qué digo el Dante, como si él fuera el mismísimo Virgilio" (66, 71 y 142). Como sabe el lector, Arturo Belano también es poeta, al igual que Roberto Bolaño.

En la novela Los detectives salvajes el pedante abogado y poeta Xosé Lendoiro narra su encuentro con Arturo Belano. En la rural Galicia un niño de nombre Elifaz se ha caído por un sima o grieta "profunda e insondable" apodada "Boca del Diablo" (Bolaño Los detectives salvajes 429). Los lugareños temen bajar a salvarlo, hasta que uno desciende, pero lo vuelven a izar tras oír un "aullido sobrehumano" (430). Cuando por fin consigue hablar, afirma haber visto al diablo. Ante la pasividad de todos, Arturo Belano desciende por la sima y salva al niño. La alegría posterior se celebra con una "fiesta gallega en la montaña" (434). Un par de años después, Lendoiro y Belano tiene frecuentes encuentros en Barcelona, pero 
el primero no consigue involucrar al segundo en su influyente círculo de literatos, como si ni la fama ni el dinero le interesasen a Belano. Dejan de verse.

Otros personajes de esa misma novela entran en escena. Uno de ellos, Guillem Piña, un viejo amigo de Belano, narra que éste fue a visitarlo para contarle que le iban a "hacer una mala crítica" (473). A continuación, se establece un diálogo esclarecedor, siempre según el narrador Piña:

¿Pero dónde está el problema?, dije. El problema, dijo él, es que el crítico, un tal Iñaki Echavarne, es un tiburón. ¿Es un mal crítico?, dije yo. No, es un buen crítico, dijo él, al menos no es un mal crítico, pero es un jodido tiburón. (474)

El nombre del crítico literario ficticio alude, obviamente, a Ignacio Echevarría. Y si la semejanza de nombres es significativa, también lo son otros datos relativos a las contiendas literarias de Echevarne y Echevarría. Echevarne habría hecho una crítica muy dura a un amigo del escritor Aurelio Baca, un "santo varón madrileño" $(476)^{8}$, como lo define algunas páginas más adelante el personaje Jaume Planells. Varios indicios dispersos por la novela, y en especial esa denominación de "santo", permiten que el lector reconozca trazos del escritor Antonio Muñoz Molina en la figura literaria de Aurelio Baca. El lector informado sabe que la mujer de Muñoz Molina, Elvira Lindo, también escritora, suele publicar unas columnas semanales sobre temas sociales en El País, y con frecuencia alude o aludía a su marido como "mi santo". Épocas ha habido en que ambos han ocupado espacios semanales propios en El País; ella bajo una máscara de ligereza intelectual, él con una pose moralista.

Recapitulando, el personaje Belano está asustado porque el crítico literario Echavarne va a hacer una crítica sobre su última publicación y teme su juicio, pues años atrás Echavarne había hecho una crítica demoledora sobre una novela de un amigo de Aurelio Baca, quien salió en defensa pública de su amigo, contraatacando duramente la reseña de Echavarne. Si el lector está bien informado, recordará que el crítico Ignacio Echevarría criticó con cierta saña la novela El jinete polaco (1991) de Antonio Muñoz Molina, en su momento recién ganadora del Premio Planeta. La reseña era larga e intentaba comprender la novela, encuadrarla entre las otras de Muñoz Molina, valorar la novedad que aportaba, pero su conclusión rozaba la consideración de fracaso literario:

[C]on todas sus vísceras de hombre y de escritor puestas en juego, Muñoz Molina podría haber llegado mucho más lejos. Si no es así, si El jinete polaco, con toda su intensidad, no alcanza literariamente la hondura del empeño que alienta la novela -y la sostiene-, es por una incontinencia a la que no sirven de coartada la emoción, ni la nostalgia, ni la sinceridad, ni todas sus melodías (por cierto que las canciones desempeñan un importante papel en el texto). De tal torma que, a la postre, y muy a pesar suyo, al narrador puede reprochársele lo que él dice de su abuelo: que "fueron las palabras las que le hicieron perderse, únicamente el brillo de las sonoras palabras que tanto le gustaban”. (Echevarría Trayecto 76)

\footnotetext{
${ }^{8}$ La denominación posiblemente no haya gustado a Muñoz Molina, caso se haya sentido identificado con el personaje Aurelio Baca. Algunos años después, recuérdese que Los detectives salvajes es de 1998, cuando Muñoz Molina publicó Sefarad (2001), tuvo eco en la prensa española la polémica literaria entre el escritor austríaco Erich Hackl y Antonio Muñoz Molina. El artículo de Hackl que detonó la controversia se titulaba "El caso Sefarad. Industrias y errores del santo de su señora" (Lateral 81, junio de 2001). En su contestación, Muñoz Molina hizo hincapié en censurar la denominación que se le aplicaba -"santo de su señora"-; crítica que hizo extensiva a la redacción de la revista Lateral, por haberse dejado llevar por el chiste fácil (Lateral 79-80, julio-agosto de 2001).
} 
Años después, el cinco de octubre de 1996, Echevarría arremetería, de forma mucho más amable, contra una novela de Rafael Chirbes, La larga marcha, autor al que ya había elogiado anteriormente por otras novelas. Ese supuesto ataque a Chirbes no debió gustar a Muñoz Molina, quizás incluso se acordó de la crítica a El jinete polaco, de cinco años antes. Cuatro días después, el nueve de octubre de 1996, publicaba Muñoz Molina un artículo titulado "En folio y medio" en el que atacaba a "un presunto crítico llamado Ignacio Echevarría" (38) y salía en defensa de la novela de Chirbes, autor que elogia enfáticamente: "Cada vez que yo abro una novela de Rafael Chirbes no puedo dejarla hasta el final. Cuando son breves, la última página se me convierte en el anticipo del regreso a la primera, y con suerte consigo apagar la luz a las dos de la madrugada" (38). No interesa ahora profundizar en los ácidos comentarios vertidos por Muñoz Molina contra Echevarría, que serían elogiados por Justo Serna al estallar el "caso Echevarría” ocho años después: "Hace diez [sic] años, en un artículo, Antonio Muñoz Molina trató de enfrentarse al gran mandarín de la reseña. ¿Lo recuerdan? En folio y medio se titulaba aquella pieza memorable" ("“El caso Echevarría"” 15). Tampoco interesa volver a leer la respuesta de Echevarría, Glosas polacas, del 18 de octubre de 1996, y también publicada en El País. Esos textos sirven para constatar que Echevarría ya se había labrado enemigos de peso.

Si se aceptan estas relaciones biográfico-ficcionales aquí propuestas, que relacionan a Roberto Bolaño con Arturo Belano, a Ignacio Echevarría con Iñaki Echavarne y a Aurelio Baca con Antonio Muñoz Molina, es comprensible que el personaje Arturo Belano tema una inminente crítica del "tiburón" Echavarne 9 . Si Belano fuese un escritor que juzgase su éxito de acuerdo a la lista de ventas, una crítica negativa podría sobrellevarse, pero el personaje Belano ha bajado a la sima "Boca del Diablo", le ha visto la cara a la muerte. El lector puede interpretar que escribir, para Arturo Belano, sea algo así como "saber meter la cabeza en lo oscuro, saber saltar al vacío, saber que la literatura básicamente es un oficio peligroso", como opina Roberto Bolaño. En ese caso, la mera posibilidad de una crítica negativa no puede quedar sin respuesta, pues podría poner en cuestión la autenticidad, no tanto la calidad, de un trabajado y vivido proyecto literario. Si una novela puede ocasionar riesgos colaterales, tanto para el autor como para algún lector, se admite implícitamente que también una crítica literaria pueda ser un arma de destrucción masiva.

El personaje Belano propone como solución un duelo, según se desprende de sus palabras citadas en la narración del personaje Guillem Piña: "[Y]o voy a ser el sparring de Echavarne para su segundo round o su octavo round con Baca, dijo Arturo. [...] Lo voy a desafiar a duelo, dijo Arturo finalmente" (Bolaño Los detectives salvajes 475). A continuación, se discute el tipo de armas: "Yo sugerí globos hinchados de agua con tintura roja. O una pelea a sombrerazos. Arturo se empeñó en que tenía que ser con sables" (475). Es decir, la pelea no es un juego, sino que tiene que ser con armas de caballeros, como le hubiese gustado a don Quijote. En resumidas cuentas, el duelo tiene lugar en una playa desierta,

\footnotetext{
${ }^{9}$ El lector familiarizado con la obra de Roberto Bolaño puede enumerar fácilmente otros textos suyos en los que comparece un crítico literario. En concreto, se puede citar por partida doble la novela Nocturno de Chile (2000). Por un lado, el personaje Farewell recuerda al crítico literario Hernán Díaz Arrieta (1891-1984), más conocido bajo el pseudónimo de Alone, y por otro, la figura de Sebastián Urrutia Lacroix se empareja con el también crítico literario José Miguel Ibáñez Langlois (*1936), que suele firmar sus artículos con el nombre de Ignacio Valente.
} 
próxima a Barcelona, y una ex-novia de Belano, Susana Puig, siguiendo sus precisas indicaciones, lo observa todo desde la distancia, sin poder intervenir ni tampoco entender cabalmente todo lo que está pasando:

En el centro de la playa sólo quedaba Arturo y el primer hombre. Entonces levantaron aquello que sostenían en las manos y lo entrechocaron. A primera vista me parecieron unos bastones y me reí, pues comprendí que lo que Arturo quería que yo viera era eso, una payasada, una payasada con un aire extraño, pero definitivamente una payasada. Pero luego una duda se abrió paso en mi cabeza. ¿Y si no fueran bastones? ¿Y si fueran espadas? (Los detectives salvajes 469)

La escena se mueve entre el juego, la vida y la literatura, todo depende del punto de vista.

En los últimos años del siglo XX el proyecto literario de Roberto Bolaño estaba adquiriendo coherencia, estaba tomando forma discursiva, tanto literaria como expositiva. Tanto es así que otros fueron capaces de verlo, intuirlo. Entre ellos el propio crítico Ignacio Echevarría, al que le unía una amistad surgida alrededor de 1997, cuando éste presentó en Barcelona la novela Llamadas telefónicas (1997). Y parece ser que la amistad se cimentó sobre todo a base de llamadas telefónicas: Bolaño en Blanes, Echevarría en Barcelona. La súbita dimisión de El País de Ignacio Echevarría podría incluso interpretarse, a posteriori, como un gesto literariamente bolañiano.

También Javier Cercas vio esa preocupación vital de Bolaño por narrar y recuperar la memoria comunicativa de una generación latinoamericana que se había embarcado en el sueño de la utopía. Y lo consignó por escrito unos años después en la novela Soldados de Salamina (2001). Resume el personaje Javier Cercas su conversación con el personaje Roberto Bolaño:

\footnotetext{
Antes de dormirse esa noche, Bolaño sintió una tristeza infinita, no porque supiera que iba a morir, sino por todos los libros que había proyectado escribir y nunca escribiría, por todos sus amigos muertos, por todos los jóvenes latinoamericanos de su generación -soldados muertos en guerras de antemano perdidas- a los que siempre había soñado resucitar en sus novelas y que ya permanecerían muertos para siempre, igual que él, como si no hubieran existido nunca [...]. (Soldados de Salamina 152)
}

Cuando se tiene un proyecto literario tan vasto y necesario como el de Roberto Bolaño recordar y narrar los sueños de una generación entera- o se ha bajado a la "Boca del Diablo", como hizo el poeta Arturo Belano, defender un libro propio con la propia vida no puede ser visto como algo absurdo. Por lo menos no es absurdo desde el punto de vista literario.

Ya en una de las primeras novelas de Roberto Bolaño, El Tercer Reich, fechada en 1989 pero sólo publicada póstumamente en febrero de 2010, el protagonista y narrador marcaba el camino para sus siguientes novelas: “¿Cuántos han mirado el abismo?” (246).

\section{Bibliografía}

AZNÁREZ, Malén (2004): "El 'caso Echevarría”". El País, 19 de diciembre, 16.

BOLAÑO, Roberto (2002): Los detectives salvajes. Barcelona: Anagrama.

BolaÑo, Roberto (2005): "Discurso de Caracas", in Entre paréntesis. Edición de Ignacio

Echevarría. Barcelona: Anagrama, pp. 31-39.

BoLAÑO, Roberto (2004): "La visita al convaleciente", in Los perros románticos. Barcelona:

Alcantilado, pp. 40-44.

Bolaño, Roberto (2007): Amuleto. Barcelona: Anagrama.

BOLAÑO, Roberto (2010): El Tercer Reich. Barcelona: Anagrama. 
CERCAS, Javier (2001): Soldados de Salamina. Barcelona: Tusquets.

CONTE, Rafael et alii (2004): "Preocupación". El País, 18 de diciembre, 15.

ECHEVARRÍA, Ignacio (1998): “Un círculo vicioso”. Revista de Libros, abril, 16:41.

ECHEVARRÍA, Ignacio (2003): “El escritor imaginado". El País, suplemento Babelia, 22 de noviembre, 10.

ECHEVARríA, Ignacio (2004): "Una elegía pastoral”. El País, suplemento Babelia, 4 de septiembre, 4.

ECHEVARRÍA, Ignacio (2004): “Carta abierta a Lluís Bassets", 9 de diciembre, 2004. Web [se encuentra en varios blogs, entre ellos, escolar.net, consultado el 15 de mayo de 2012].

ECHEVARRÍA, Ignacio (2004): “"Caso Echevarría”". El País, 20 de diciembre, 15.

ECHEVARRÍA, Ignacio. "Respuesta a Juan Goytisolo" (2005): El País, 29 de enero, 14.

ECHEVARRÍA, Ignacio (2005): Trayecto. Un recorrido crítico por la reciente narrativa española. Barcelona: Debate.

ECHEVARRÍA, Ignacio (2007): Desvíos. Un recorrido crítico por la reciente narrativa latinoamericana. Santiago de Chile: Ediciones Universidad Diego Portales.

EchevarríA, Ignacio (2009): “Cuento de Navidad”. El Cultural. Suplemento de El Mundo. 24 de diciembre. Web [15 de mayo de 2012].

Goytisolo, Juan (2005): “Cuatro años después”. El País, 28 de enero, 16.

MuÑoz Molina, Antonio (1996): "En folio y medio". El País, 9 de octubre, 38.

SERNA, Justo (2004): ““Caso Echevarría””. El País, 20 de diciembre, 15. 